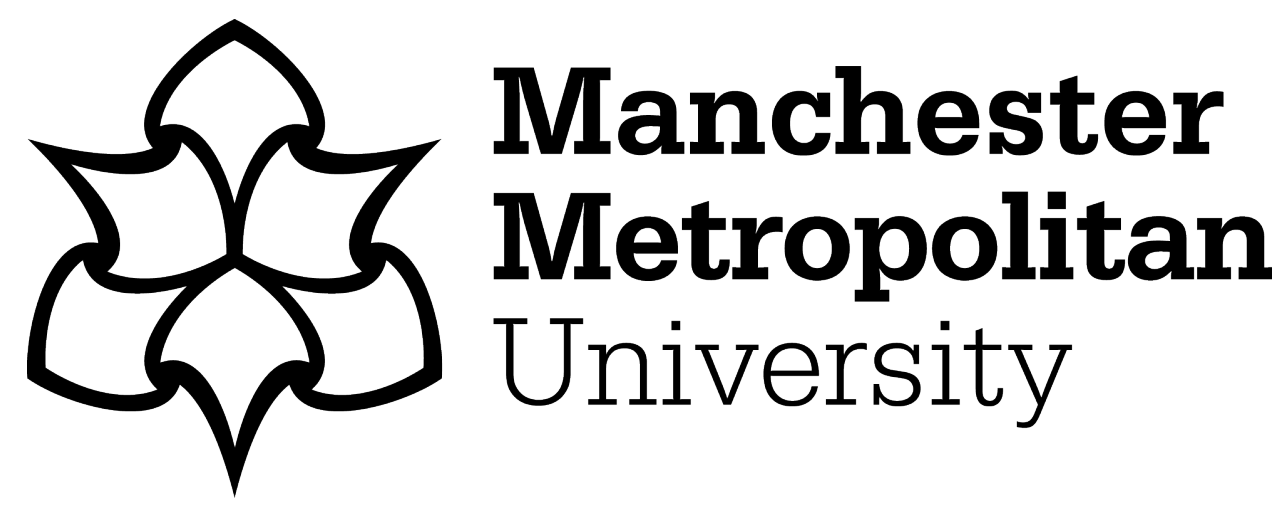

Akram, Sadiya (2017) Representative bureaucracy and unconscious bias: Exploring the unconscious dimension of active representation. Public Administration, 96 (1). pp. 119-133. ISSN 0033-3298

Downloaded from: https://e-space.mmu.ac.uk/619465/

Version: Accepted Version

Publisher: Wiley

DOI: https://doi.org/10.1111/padm.12376

Please cite the published version 


\section{Representative Bureaucracy and Unconscious Bias: Exploring the Unconscious Dimension of Active Representation ${ }^{1}$}

\section{Introduction}

Scholars of public administration have long been concerned with the representative aspects of bureaucracies (Kingsley, 1944; Pitkin 1967; Krislov, 1974; Mosher 1968/1982). ${ }^{2}$ Ever since Kingsley's (1944) observation that the 'middle-class state' perpetuated its own values in administrations by recruiting only those who 'have been educated according to the traditional pattern of the ruling class' $(1944$, p.151), the representation of minorities in bureaucracies continues to be a pressing issue.

Mosher's (1968/1982) distinctions of active and passive representation have helped to further thinking on this issue. Whilst Kingsley was more concerned with the consequences of poor representation, and with social groups rather than individuals, Mosher focuses our attention on how individuals bring different 'perspectives, knowledge, values, and abilities' (1982: p.16) to bear on issues, leading him to identify two types of representation. Passive (or descriptive) representation 'concerns the origin of individuals and the degree to which collectively, they mirror the whole of society' (1982: p.15). Active representation, meanwhile, refers to when 'individuals (or administrators) are expected to press for the interests and desires of those whom they are presumed to represent, whether they be the whole people or some segment of the people' (1982: p.14). As evidence of the further refinement of these distinctions, there is now a growing literature on the relationship between passive and active representation (Andrews and Miller, 2013; Thompson, 1976; Saltzstein, 1979). This article contributes to this debate, focusing specifically on active representation and how it occurs.

Kingsley is explicit about the fact that most of what is now called active representation was the result of in-group socialization. He contends:

\footnotetext{
1 Thanks to Dave Marsh, Kim Hutchings and Mike Kenny for comments on earlier drafts of this article. I am also grateful to Meredith Edwards and Mark Evans at IGPA, University of Canberra, for fruitful discussions on unconscious bias during my time as a Research Fellow in Canberra. Thanks, finally, to the Public Administration reviewers for their helpful advice and suggestions.

${ }^{2}$ It should be noted that other notable discussions of representation exist, but which are not the focus here. Primary amongst these is Birch - see Birch, A. (1964). Representative and Responsible Government. London: Allen and Unwin.
} 
And the Civil servants behaved in these fashions, not because they were taking orders from the representatives of the vested interests, but because they themselves thought in a similar manner. They were immersed in the ideologies of their class and they behaved accordingly (Kingsley, 1944: 291).

Representation of class interests is, in Kingsley's view, not a conscious or intentional process, but occurs at a subtler level, through socialisation. Similarly, Krislov and Rosenbloom (1981) argue that, even if we accept that bureaucrats are attempting to be socially representative, there is the issue of whether they will 'retain values and attitudes stemming from their social backgrounds', which constitutes a problem if the talent pool which is selected from is largely middle class (1981, p.23). ${ }^{3}$ This continues to be an issue, even when a bureaucracy may instil its own socialisation processes, so, whilst length of time working for an organisation matters, as does the 'time-distance from one's background', as Mosher puts it: '( $t$ )he fact is that we know too little about the relationship between a man's background and pre-employment socialisation on the one hand, and his orientations and behaviour in the office on the other' (Mosher, 1982: p.16). In short then, the extant literature on active representation suggests that much of it occurs through pre-employment socialisation and occurs outside of the awareness of the individual. Furthermore, as Mosher stated back in 1968 and again in 1982, how individuals bring 'different perspectives, knowledge, values, and abilities' to bear on issues (1982: p.16) has not been sufficiently explored by the literature and so represents a gap in our understanding of how active representation occurs.

This article contributes to the representative bureaucracy literature by arguing that the dominant literature on representative bureaucracy does not reflect on the unconscious dimension of active representation. The path opened by Kingsley - "they were immersed in the ideologies of their class and they behaved accordingly" (1944, p.21) - has not been sufficiently explored to date. The work of Atkins and Wilkins (2014); Andrews and Miller (2013); and Meier and Nicholson-Crotty (2006), for example, has expanded our understanding of the impact of active representation on public policy outcomes, but there is more we can learn about how active representation occurs. This article is concerned with how agents (actively) represent interests in bureaucracies. Unconscious bias, I argue, has a role to play in how we understand value transmission, decision-making and actions in the public sector and other bureaucracies.

\footnotetext{
${ }^{3}$ See Stazyk et al. (2017) for a recent discussion of differences in values and the role of race.
} 
To this end, this article combines a focus on representative bureaucracy theory with a discussion on unconscious bias, showing how the latter can enrich our understanding of how active representation occurs. The article discusses the finding of unconscious bias in the Australian Public Service (APS) (Edwards et al. 2014) to highlight how the concept helps to explain persistent gender inequality, but also to show the limitations of an under-theorised notion of unconscious bias. As a large public sector organisation, which is committed to, but has struggled to achieve gender equality to date, the APS case study has relevance beyond Australia and serves as a useful example of the challenges of understanding and tackling unconscious bias in public sector organisations. There has been a paucity of attention paid to unconscious bias in Public Administration, but the concept has the potential to enhance our understanding of how active representation occurs in bureaucracies.

\section{Unconscious Bias}

Research is beginning to point to the existence of unconscious bias, but the concept is poorly defined in the extant literature and/or is used un-problematically. So, for example, the existence of unconscious bias was identified by recent research into persistent gender inequality in the Australian Public Service (Australian Public Service Commission, 2012; Edwards et al. 2014; Evans and Edwards 2014; Evans et al. 2014). The concept is also used in the literature examining gender inequality in commercial organisations (Genat et.al 2012; Mckinsey \& Company, 2011), while universities are providing 'unconscious bias training' for staff. Thus, there is an emerging consensus that unconscious bias exists, but the concept has received limited attention in Public Administration. However, that is not to say that the concept has not been documented in disciplines such as social and political psychology and behavioural psychology, which have long argued for the existence of 'implicit bias'. Rather, I want to argue, that such literatures take a narrow approach to the concept based on either cognition, or the automacity of behaviour, and that we need to develop a conceptual understanding of the unconscious, which recognises its disputed status and considers what role this concept can have within a broader understanding of agency. Such a concept would have relevance to Public Administration scholars interested in representative bureaucracy, as well as wider appeal across the discipline. 
Consequently, this article argues, firstly, that the unconscious represents a component of agency and, relatedly, that unconscious bias is a method through which bias is perpetuated in society. More specifically, I make two key claims: a) to understand unconscious bias, we must acknowledge that the unconscious is a contested concept and, therefore, develop a more adequate conceptual understanding of the unconscious; and b) we must pay greater attention to the concept of agency that underpins our understanding of unconscious bias, given the concept needs to be rooted in a broader discussion about agents, how they act and their role in reproducing inequality. Taking these two claims as my starting point, I develop a more adequate conceptualisation of the unconscious, which draws on Bourdieu's notion of habitus, as an element of a broader conceptualisation of agency. This involves exploring the relationship between the unconscious and other capacities of agency, such as decision-making, reflexivity and habit and placing them on a spectrum where they interact.

I acknowledge that conscious forms of bias exist, but contend that discrimination has evolved and that the focus should be on covert forms of bias as well as overt. As such, our concepts also need to evolve. More specifically, in terms of public policy, I argue that an improved understanding of unconscious bias can significantly enhance how we understand discrimination, because it suggests a need to re-focus diversity agendas away from identifying 'bad' people', who make discriminatory decisions, to identifying well-intentioned people, who are unaware of the unconscious factors that affect their decision-making. Such a proposition does not absolve individuals of personal responsibility for their discriminatory behaviour because it is unconscious, but, rather, highlights the need to regularly 'check' one's biases.

This article has four substantive sections. The first section provides context to this debate by exploring the literature on why representative bureaucracies matter. Next, I turn to the extant literature on unconscious bias, which is disparate given that it is in political and social psychology that the concept has been most utilised. Here, I begin by briefly considering research in private sector or commercial organisations, which has done most to document unconscious bias, although this work is un-theorised, merely identifying this form of bias. ${ }^{4} \mathrm{I}$ subsequently consider the social/political psychology literature, which focuses on implicit biases, but offers a de-limited perspective because it is singularly concerned with cognition. In

\footnotetext{
${ }^{4}$ It may be deemed unconventional to discuss this literature, but given that it includes recognition that unconscious bias exists, it is an important source of documentation.
} 
the light of this narrow discussion of unconscious bias in various literatures, I then outline and discuss Bourdieu's theory of habitus as a way of conceptualising the unconscious as an aspect of agency, before outlining a conceptual framework for better understanding unconscious bias.

In the third section, I demonstrate the utility of my approach by considering recent research (Edwards et al., 2014) into the Australian Public Service (APS) which argues that unconscious bias is a key way in which gender inequality is reproduced in society; that ideas about gender of which people are, at least partly, unaware can affect their behaviour, and have replaced overt discrimination as the main cause of gender inequality in the APS. Building on Edwards et al. (2014), my approach offers a fuller explanation of this process by theorising and elaborating on the concept of unconscious bias and linking it to an underpinning concept of agency. The final section of the article returns to the methodological implications of the concept of unconscious bias and the framework outlined. Here, I consider some of the methodological challenges in analysing unconscious bias, which requires new methods and techniques of inquiry. I conclude by returning to debates about bureaucratic representation with some tentative suggestions for ways forward for unconscious bias training programmes.

\section{Representative Bureaucracy Theory}

Research on representative bureaucracy theory has found that the level of diversity within an organization impacts on its ability to represent the public it serves (Riccucci and Van Ryzin, 2016; Mosher, 1982; Skorkjaer, 2011; Sowa and Selden 2003; Pitkin 1967). The diversity literature also corroborates this (Linos et al. 2017; Stazyk et al. 2017; Skorkjaer, 2011; Pitts, 2005). Research has also demonstrated that more representative bureaucracies tend to be better performing organizations with improved service delivery, particularly for unrepresented or minority groups (Wilkins, 2007; Meir and Nicholson-Crotty 2006). The issue is far from simple, and Christensen et al. (2017), for example, highlight the challenge of reconciling (geographic) representation with the recruitment of 'specialized expertise' in bureaucracies.

Creating representative bureaucracies remains an ongoing challenge and applying a gender lens to bureaucracies offers some insight into the extent of the problem. The feminist analysis of bureaucracy stresses that, rather than being neutral, public organizations are in fact gendered. Specifically, they are characterized by hierarchical organization, a division of labour and technical rationality, meaning privileging task-orientated, rather than relational skills (Mackay 
and Rhodes, 2013; Johnston 2017). A masculine culture of authority abounds, whilst femininity is associated with emotional and relational activities (Mackay and Rhodes, 2013). For example, Mackay and Rhodes (2013) analyse the everyday practices of femininity and masculinity and show how they shape gender norms in central government departments. They found that 'rules, practices and beliefs' reflect and reproduce unequal gender relations (2013: p.586). They also recognise that 'daily practices of gender are often unthinking rather than purposive' or are 'taken-for granted' (2013: p.586). This hints at the need to move beyond the visible and explicit to understand institutional behavior and the mechanisms through which inequality is reproduced.

If we accept that bias exists, and that it is reflected in stereotypes, norms, opinions and workplace culture, we need a better understanding of whether it occurs through conscious or unconscious behavior; which should also inform our strategies to address it. This point is echoed by Johnston in her research on gendered patterns and biases within network governance. She argues that there is a need for 'qualitative research into the unconscious mobilization of bias against women in collaborative governance' (2017: p. 156). This is a worthy endeavour, but, before it can happen, we need greater clarity about what we mean by unconscious bias; the task of this paper.

In the past women and minorities were kept out of the workplace by explicit rules and practices, today the discrimination is subtler. Consequently, there is a need to develop new conceptual tools to understand it. The first step in the analysis is to explore the extant and disparate literature on unconscious bias. The existence of unconscious bias as an obstacle to women's career progression has been discussed particularly in the private sector (Genat et al., 2012; AIM, 2011; Mckinsey \& Company, 2011; Ross, 2008) and grey literature (Australian Department of Defence, 2011; Australian Department of Treasury, 2011). There is also discussion of 'implicit' bias in the social and political psychology literature. ${ }^{5}$ This literature provides empirical evidence of unconscious/implicit bias, but, like the research into the APS

\footnotetext{
${ }^{5}$ For social psychology literature which discusses implicit bias see: Gaertner, S.L. and Dovidio, J.F. (2005). Social Psychology Understanding and Addressing Contemporary Racism. Journal of Social Issues. Vol. 61 (3). Pp. 615-639. Also see: Payne, B.K., Gawronski, B., (2010). A history of implicit social cognition in Gawronski, B., Payne, B.K. (eds.), Handbook of Implicit Social Cognition: Measurement, Theory, and Applications. Guilford Press: New York.
} 
discussed in Section 3 below, individuals are viewed as having unconscious capacities, but this is underdeveloped.

\section{i. Extant literature on unconscious bias}

It is the commercial and grey literature, which has done most to advance the concept of unconscious bias, highlighting organisations' recognition that this is a pressing concern. Fig 1 outlines the range of distinctions in that literature, which are a useful starting point for the discussion here.

\begin{tabular}{|c|c|c|}
\hline Form of unconscious bias & Nature of the problem & Literature \\
\hline Gender evaluation bias & $\begin{array}{l}\text { Consistent or systematic devaluing of } \\
\text { women relative to men }\end{array}$ & Genat et al. 2012 \\
\hline Gender backlash & $\begin{array}{l}\text { Stereotype bias in which women (or } \\
\text { men) who behave counter- } \\
\text { stereotypically experience negative } \\
\text { social or economic effects }\end{array}$ & Genat et al. 2012 \\
\hline $\begin{array}{l}\text { Malestream understanding of } \\
\text { leadership characteristics }\end{array}$ & $\begin{array}{l}\text { Perception that women's leadership } \\
\text { style (warm, friendly, less competitive) } \\
\text { is not as valued as men's (assertive, } \\
\text { ambitious, decisive). }\end{array}$ & $\begin{array}{l}\text { Catalyst } 2004 \\
\text { Genat et al. } 2012\end{array}$ \\
\hline $\begin{array}{l}\text { Perception that women } \\
\text { prioritise family over work }\end{array}$ & $\begin{array}{l}\text { Perception of women as primary care- } \\
\text { givers; takers of maternity leave, which } \\
\text { is perceived as disruptive and a choice } \\
\text { to prioritize family over work. }\end{array}$ & $\begin{array}{l}\text { Sanders et al. 2011; } \\
\text { McKinsey and } \\
\text { Company, } 2011 .\end{array}$ \\
\hline
\end{tabular}

\section{Fig 1. Forms of unconscious bias}

Genat et al. (2012) identify two forms of unconscious bias: gender evaluation bias; and gender backlash. Gender evaluation bias involves a consistent, or systematic, devaluing of women relative to men in occupational settings. Gender backlash involves a form of stereotype bias in 
which women (or men) who behave counter-stereotypically experience negative social or economic effects.

Genat et al (2012) suggest that, when fully competent women aspire to leadership, which is often associated with stereotypically male characteristics, or to other male-dominated occupations, they experience a heavy, and hidden, handicap due to unconscious bias. Compared to their male peers, women are down-rated irrespective of whether they behave in stereotypically masculine or stereotypically feminine ways. In short, women are said to experience evaluation penalties regardless of whether they are good or bad at their job. Deepening the problem, backlash bias steps in when women attempt to act in a stereotypically male way. So, for example, if women self-promote like men, they become less likable, which may work against them. This research highlights the paradox in which women in senior roles find themselves, namely that they are penalized for behaving in stereotypically male or female ways.

The pervasive functioning of stereotypes relating to the typical characteristics of men and women, and to defining what makes a good leader, are central to understanding gender inequality and how the unconscious is implicated. Our understanding of men and women develops from a young age, and will, in later life, inform our evaluations of colleagues in the workplace. The private sector literature highlights the pervasive influence of stereotypes premised on traits that are typically expected of men, such as being ambitious, assertive, decisive and self-reliant (Genat et al. 2012; Catalyst 2004). These attributes are also associated with good leadership. Women, in contrast, are associated with being warm, sensitive, friendly or communal and less competitive in a male environment. Whilst these attributes are typically valued, they are deemed less important for most leadership roles than stereotypical male behaviour. Ultimately, gender stereotypes misrepresent the true talents of women leaders and position women in an unfair and potentially no-win scenario.

\section{ii. Social and Political Psychology and 'implicit' bias}

Whilst the terminology differs, social psychology's notion of implicit bias resembles the notion of unconscious bias discussed here. In social psychology, implicit bias is opposed to explicit bias, which reflects the attitudes or beliefs that one endorses at a conscious level. Implicit bias, then, is the bias in judgment and/or behaviour that results from cognitive processes (implicit 
attitudes and implicit stereotypes) that operate at a level below conscious awareness and without intentional control. Ergo, implicit behaviour relies on cognitive processing and derives from automatic behaviour, rather than conscious intentional behaviour. Implicit bias relies on an associationist theory of memory, and the key insight here is that memory works in cascading fashion, so, as one mental construct is activated, it automatically - i.e. without intentionality activates associated constructs. For example, exposure to a picture of fruit activates memory of apples. Time of reaction is important and faster reactions imply greater mental association.

Research in this area has indicated that implicit bias has implications for understanding attitudes toward members of socially-stigmatized groups, such as women and ethnic minorities. While controlled, or more conscious, processing is thought to be voluntary, automatic processing unfolds without attention and can be hard to suppress voluntarily (Greenwald and Banerji, 1995). Drawing on social psychology, the concept of implicit bias has also travelled to political psychology, with Galdi, Gawronski and Arcuri (2015), for example, arguing that implicit behaviours can help to understand political attitudes, behaviour and future political behaviour (also see Arcuri et al. [2008] and Burdein et al. [2006]).

Social psychology's understanding of implicit bias is premised on the fact that what a person says is not necessarily a good representation of all her feelings and thoughts, nor of how she will behave. Using cognitive mapping, the central advance of research on implicit bias and social cognition is the apparent ability to measure people's attitudes without having to ask them directly. This perspective has had some impact on diversity practices in the workplace and offers practical strategies for addressing bias. For example, Implicit Association Tests (IAT) have now become a popular training tool in diversity programmes and are built around the principle of recognising biases, addressing where they come from and why they may be harmful. ${ }^{6}$

As this discussion indicates, there is much support for the claim that inequality is reinforced through unconscious or implicit forms of bias. Whilst this body of work is important for documenting non-conscious forms of bias, it can only take us so far. Much of the commercial

\footnotetext{
${ }^{6}$ Similarly, recent developments in the field of cognitive neuroscience demonstrate a link between implicit, but not explicit racial bias and neural activity in the amygdala; a region in the brain (Phelps et al. 2000; see also Stanley, Phelps and Banaji, 2008). The other notable recent research on unconscious bias is Bohnet's (2016) work, which is informed by social psychology, behavioural science and neurobiology.
} 
literature is atheoretical and operates with little, if any, discussion of what it means by the unconscious. Social and political psychology has an understanding of implicit bias, but this is based on the automatic processing of the brain and cognition, so, again, can only take us so far. In using the term 'implicit', as opposed to unconscious, social psychology limits its remit to cognition and the brain - and the automatic processes affecting the brain. The unconscious is not invoked in the concept of implicit bias; the focus is upon the brain and cognition. I suggest that, to understand unconscious bias, we must move beyond automatic cognition to theorise the unconscious and unconscious bias, within a broader understanding of agency. Such a perspective moves beyond a narrow focus on mental associations and reaction times that are central to social psychology's understanding of implicit bias. A further issue and a strength of the conception of unconscious bias developed here, is that it is important to move beyond a singular focus on unconscious bias, and consider instead how it interacts with other capacities of agency, particularly an individual's capacity to reflect on her actions. In short, in the extant literature, discussion of unconscious bias often takes place in a vacuum and therefore makes little sense in terms of an overall understanding of agency, or how individuals understand how they, or others, act.

\section{Defining Agency}

A concept of agency underpins all conceptions of human behaviour, yet it is a neglected concept. The neglect of the unconscious aspect of agency reflects the focus in the social sciences on rational, reasoning and reflexive agents (Akram, 2012; Akram and Hogan, 2015). In response, I discuss Pierre Bourdieu's (1977) concept of habitus and its unconscious aspects. I argue that habitus has clear unconscious elements, although they were neglected in Bourdieu's writing on the subject ${ }^{7}$ and that the concept can enhance our understanding of unconscious bias.

\section{i. $\quad$ Bourdieu and the unconscious habitus}

The 'unconscious' is never anything other than the forgetting of history which history

\footnotetext{
${ }^{7}$ An important clarification affects this discussion. For most readers, reference to a notion of the unconscious immediately raises the spectre of Freud (1927/1962) and psychoanalysis; approaches which have largely dominated discussion on this topic. The concept of the unconscious has a history in psychoanalysis, which is substantively different to the notion that is hinted at in Bourdieu's own writing, but also the notion advocated in this paper.
} 
itself produces by incorporating the objective structures it produces in the second nature of habitus...' (1977: pp.78-79).

Offered as a more nuanced way to understand the relationship between structures and agents, Bourdieu's concept of habitus has been much discussed, but its unconscious aspects have received less explicit attention. However, as the quote above makes clear, Bourdieu's texts contain references to the 'unconscious', or to how actions are carried out 'quasi-consciously' (1977: p.76). I suggest habitus is premised on a complex relationship between the conscious and the unconscious and that, for Bourdieu, this is central to understanding how structure and agency interact - or how agents are affected by structure and, in turn, are implicated in how structure is reproduced. By extension, I propose that the unconscious habitus provides a useful framework for understanding unconscious bias, or how unconscious biases take root within habitus over the life course and may become deeply embedded and outside of the agent's awareness. My aim in this section is to explore the concept of habitus and highlight how its functionality is, in fact, dependent upon it operating from a partially unconscious platform.

Bourdieu claims that the individual's habitus is the product of her upbringing and, more particularly, of her class (1977: p.87). He explains that habitus brings about a: 'unique integration, dominated by earliest experiences... Thus, for example, the habitus acquired in the family underlies the structuring of school experiences..., and the habitus transformed by schooling itself diversified, in turn underlies the structuring of all subsequent experiences, and so on, from restructuring to restructuring' (1977: p.87). Bourdieu suggests that habitus should be a: 'subjective but not individual system of internalised structures common to all members of the same group or class' (1977: p.86). Habitus is a system of 'dispositions' which Bourdieu defines as 'having a meaning close to that of words such as structure' or 'pre-disposition, tendency, propensity...' (1977: 214 emphasis in the original). Habitus, then, provides a mechanism for understanding how social structure is reproduced and, in this way, both habitus and social structure are continually reconstituted.

The unconscious elements of habitus are reflected in how it operates and they inform the agent's 'practice' in a structured world. Agents do not always engage in an explicit way with the world's rules or structures. The fact that they do engage with rules and structures on a regular basis requires a different principle of action, hence the unconscious. Habitus aims to locate the body in the social world and the social world in the body, so the social world is 
experienced as embodied. Bourdieu describes the process of interaction between structures and agents in a very interesting way, using an analogy which sees the social world as 'the game', and the agent as the 'game player'. He presents habitus as the 'feel for the game', suggesting that, because of this sense of awareness or 'feel', 'the social game (is) embodied and turned into second nature' (1990a: p.63). Bourdieu goes on to suggest that the: 'good player does at every moment what the game requires. That presupposes a permanent capacity for invention, indispensable if one is able to adapt to indefinitely varied and never completely identical situations' (1990a: p.63).

My broader argument here is that habitus provides a useful way of conceptualising unconscious bias. Essentially, habitus can structure how agents think about gender, and indeed other aspects of their lives. The unconscious habitus provides a mechanism to understand how agents internalize thoughts about gender roles, about responsibility for child-care and about leadership styles, as 'durable, transposable dispositions' (Bourdieu, 1977). Important here is the point that has been acknowledged by the existing literature on unconscious bias discussed earlier, that these perceptions develop over the course of a lifetime, and may begin to be reinforced as gender stereotypes from childhood.

A notion of the unconscious as a component of agency is also central for understanding how structure affects agency and, in turn, how structure is reproduced. A concept of the unconscious aids our understanding of social structure in two ways. First, it helps to explain how agents are affected by social structures such as gender independent of their awareness of it. Second, this unconscious engagement with social structure helps to explain how gender is reproduced as a social structure. Influencing agency through the unconscious is not the only way in which gender impacts on agency, nor is the unconscious alone responsible for reproducing gender as a social structure in society. However, this account complements our understanding of more explicit and conscious methods through which gender impacts on society and, therefore, enhances our understanding of the interaction between structure and agency.

At this stage, it would be reasonable to question the role of conscious action in the habitus. Does an emphasis on unconscious action mean that habitus cannot be a site of conscious and reflexive behaviour? Bourdieu's critics have argued that the presence of the unconscious in habitus affects or reduces conscious actions and thoughts (Elder-Vass 2007; Jenkins 2002). The same authors have, to various degrees, also argued that habitus is an overly determinist 
concept, although Bourdieu would disagree. However, I would argue that stating that agents act in an unconscious and habitual way in terms of everyday structural interaction is not the same as arguing that agents have no conscious and reflexive capabilities, rather it is to argue that structural and agential interaction often occurs in a mundane and habitual manner.

\section{ii. Exploring the interplay between unconscious and other agential capacities}

It is worth expanding on the relationship between the unconscious and conscious and other aspects of agency to show their interplay, whilst also producing a more complex understanding of agency. Here, I focus on the interplay between the unconscious and reflexivity, decisionmaking and habit in the habitus. This is particularly important for recognising how, for example, well-intentioned people can also engage in unconscious bias, without necessarily realising it.

\section{a) Reflexivity}

Reflexivity is defined as 'the (agents) regular exercise of the mental ability... to consider themselves in relation to their social contexts and vice versa' (Archer, 2012. p.1). Accepting the unconscious as a component of agency does not negate the fact that agents have reflexive capabilities, but underlines the point that the unconscious also affects reflexivity, because some biases are deeply ingrained within us. Habitus, of course, can be a site of conscious reflexivity about gender roles. Individuals are often reflexive about gender, as well as other things of concern to their lives. Rather, what I am arguing, contra Archer (2012), is that agents are not routinely reflexive, nor is it their dominant mode of behavior, but, instead, agents often act habitually, in a non-reflexive, unconscious, way (Akram and Hogan, 2015). This is how habitus works. Agents have values and orientations on which they reflect, but they also have some that do not reflect on; so, these values are unconscious.

Bourdieu has often been criticised for neglecting reflexivity in habitus (Archer, 2012; Jenkins 2000, Elder-Vass 2007). The response to this, which I would endorse, has been that reflexivity operates in relation to habitus and not outside of it (McNay, 1999). Moreover, as McNay argues (1999), reflexivity, or enacting change in one's life, is often difficult, and does not occur in a vacuum uninfluenced either by other characteristics of agency, or by social structure.

b) Decision-Making 
When interviewing candidates for a position, or for a promotion, it is reasonable to expect that those in charge of the process would engage in a process of considered and deliberate reflection about the various merits of candidates before deciding. This process often assumes that decision-making takes places in a vacuum, based on rational reasoning and judgment. One shortcoming of the existing research in this area is that it does not account for the potential influence of unconscious processes on decision-making and conscious reasoning. In his research into this issue, Singh (2005) found that his participants made decisions (on policy issues and personal preferences) quickly with little external evidence to support them, even though many reported having little, or no, knowledge relating to the decision. Singh argues that people have little or no awareness of their actual decision-making processes, so they are not aware of the actual reasons for their decisions or actions. This is the case even when/if they can give reasons when prompted to do so (post-hoc reasoning). These findings do not support traditional, purely conscious, models of judgment and decision-making. Instead, they point to the importance of the interactive nature of various agential characteristics and to the impact of the unconscious on the more conscious capacities of agency.

c) Habit

Habit is also important for understanding how unconscious bias develops. Habit, however, has been neglected in more recent social theory partly because of the use of the term in behavioural psychology, where it is often interpreted as a biological reflex. Another reason for its declining importance is that it is antithetical to a notion of reflexivity. In Archer's view, agents today are becoming increasingly reflexive in their lives and this reduces their reliance on habit (Archer, 2012).

Bourdieu, however, recognises the importance of habit to agency, arguing that it plays an important role in habitus. Swartz suggests that habitus implies a 'force of habit', which drives behaviour, without determining it (Swartz, 2002, p.665). As Bourdieu himself insists, agency is much more than just habits, as this would mean that agents would have little power to engage in conscious and deliberate action. Much like practices which enter the unconscious, habits may be encountered consciously or unconsciously, and, thus, reflect the importance of intentional and conscious actions. Further, conceivably, there may be a relationship between the unconscious and habit. It should also be emphasised that habits can be broken or interrupted through conscious actions, which is the main thrust of Ross' (2008) techniques for tackling unconscious bias. 


\section{iii. $\quad$ Spectrum of Characteristics in Agency}

Central to my argument for the unconscious habitus, is the need to conceptualise agency as a spectrum. The spectrum would include conscious behaviour, habit, reflexivity, decisionmaking and the unconscious; all discussed here. This list is not exhaustive; a task beyond the scope of this article. The aim of a creating a spectrum is to emphasise the range of factors that construct agency, and how they interact. One principle of agency may dominate in one scenario, whilst others exist in the background.

The unconscious is important for agency, because it reflects the principle that the sociopolitical world affects agents in ways which they cannot necessarily control, and that we may behave in ways of which we are not necessarily conscious, hence unconscious bias. In addition, the unconscious provides a way of understanding how social structure, or gender, can affect agents in a way of which they are unaware. As such, the unconscious is critical for thinking about the relationship between agents and structures.

In the next section, I discuss research into the Australian Public Service (Edwards et al. 2014) and its finding of unconscious bias, with the aim of showing that the concept of unconscious bias utilized is under-defined and the framework discussed here offering the potential to deepen our understanding. In the absence of the author's own data, I have selected this case study because it is one of the few recent academic studies into unconscious bias in a large (public sector) organisation. There is a paucity of literature on unconscious bias in Public Administration and so this study serves as a valuable illustrative example through which to develop insights into unconscious bias although, as is discussed below, it is not without its problems.

\section{Case Study of the Australian Public Service (APS)}

'Not yet $50 / 50{ }^{\circ 8}$ (Edwards et al., 2014) is a report exploring barriers to the progress of senior women in the APS (see also Evans et al. 2014 and Evans and Edwards 2014). In June 2012, women made up $57 \%$ of the APS workforce, but only $40 \%$ of the senior executives (SES) were women (APSC ${ }^{9}$ 2012: 148). In all but four departments, women outnumbered men, but, in

\footnotetext{
8 The author of this paper was not a member of the team who researched and wrote the 'Not Yet 50/50' report, but was involved in formative discussions relating to the research during my time as a Research Fellow at the University of Canberra.

${ }^{9}$ The Australian Public Service Commission (APSC) is a statutory agency of the Australian Government.
} 
contrast, only four out of 19 departments had more women than men at the SES level. There was also considerable variation between the representation of women at different SES levels; so, $37 \%$ of Band 2 positions (equivalent to head of division) were held by women, but only $28 \%$ of Band 3 positions (the most senior rank of management below the Secretary/head level) (APSC 2012: 150). Only 20\% of departments were headed by women. There were also clear differences across Departments and Agencies, with Education, Human Services and Health being traditionally well-represented (APSC 2012). ${ }^{10}$

Starting from the premise that the barriers to women's progression are undisputed in the wider literature, so, for example, perceived differences in leadership styles or a male-stream workplace culture, the authors' key finding is that the nature of these barriers are misunderstood i.e. whether they are conscious or unconscious. The report emphasises the existence and unconscious mobilisation of bias against women in the workplace. It argues that this is reflected in dominant norms and values that advantage men with requisite skills, which are valued and recognised, while, at the same time, disadvantaging women, such that they are passed over when it comes to promotion.

Based on their findings, the authors identify four propositions about the under-representation of women in leadership positions in the APS:

Proposition 1: competing priorities/family responsibilities hinder women from taking up demanding leadership roles.

Proposition 2: negative male perceptions of a woman's ability to lead impede women's progression into leadership roles

Proposition 3: workplace structures and cultures hamper women's progress by distilling processes of unconscious bias that afford comparative advantage to men with the requisite attributes.

Proposition 4: workplace cultures and practices undermine the self-confidence and self-belief of women in seeking career advancement.

\footnotetext{
10 To ensure a broadly representative sample, the authors develop a typology of six Commonwealth Departments based on whether Departments/Agencies were more likely to have a male-streamed culture (Agencies with fewer than $40 \%$ of women in their SES); Departments/Agencies more likely to possess reasonable representation of women at the senior levels of the SES (Agencies with more than 40\% of women at the senior levels of the SES; and Departments/Agencies likely to have embedded norms and values due to longstanding history.
} 
Propositions 1 and 2 above refer directly to negative perceptions about women's competency in the workplace. The research found that men, overwhelmingly, consider 'commitment to family responsibilities' as the most important factor impacting on women's career prospects. Senior women agree that family responsibilities are an important barrier, but not to the exclusion of others. For example, over half of SES men and women in male-streamed Departments identified 'career breaks' as a crucial factor, which seems to indicate less tolerance in those Departments for career interruptions. Of course, this may relate to other barriers, such as a lack of visibility, exclusion from networks, male stereotyping and an inhospitable culture.

Proposition 4 deserves further attention, because it suggests that unconscious bias has an especially insidious effect by impacting on women's confidence and self-belief, thereby acting as an impediment to their progress. Many reasons are advanced by both men and women to explain this; they relate to, and result from, the cultural and organizational systems which reinforce messages about women's place or 'lack of fit' in leadership positions. Narratives from the study indicate that women apply high standards when assessing whether they can do the job and often express reluctance to promote themselves, whereas a very common response was that men will apply, even if they do not feel ready. This finding suggests that women often undervalue their capability and expertise, which can be explained by an organizational culture which conveys the message that women are not quite as good as their male colleagues.

Proposition 3 underpins all the others as it points specifically to unconscious bias as the mechanism which impedes women's progress by 'distilling processes of unconscious bias that afford comparative advantage to men with the requisite attributes' (Edwards et al., 2014, p.12). As this report acknowledges, the concept of unconscious bias has received little to no academic attention and the authors suggest their project is one of the first empirical studies into this issue. This is clearly an important piece of research, however, whilst it adds much to our understanding of how gender inequality operates in the workplace, it contains several gaps. Specifically, the project fails to conceptualise unconscious bias, or the unconscious, with no discussion of agency and behaviour; a point acknowledged by two of the authors in a separate piece (Evans and Edwards 2014). 


\section{i. Reconsidering the case study in light of the framework}

The 'Not yet 50/50' report is limited by its under-theorised understanding of unconscious bias. So, agents are assumed to have unconscious capacities, or indeed the capacity to engage in unconscious bias, but there is little discussion of agency. In Section 2, I outlined a conceptual frame for understanding the unconscious, and how this might be understood within a broader conception of agency. In this section, I want to draw out the lessons of this conceptual frame for the 'Not Yet 50/50' report.

In documenting the perceptions of men and women at various levels of seniority in the Australian Public Service (APS), Edwards et al. (2014) conclude that men overwhelmingly consider 'commitment to family responsibilities' as the most important factor impacting on women's career prospects (see proposition 1 noted earlier). Certainly, Bourdieu's concept of habitus provides a conceptual frame for understanding how perceptions about gender roles, such as prioritizing family over other commitments, becomes internalized as a part of the agent's habitus. Remember, habitus here refers to our outlook upon the world, incorporating mental dispositions thus it can provide a frame through which to understand how active representation occurs in bureaucracies. Further, because we know that habitus operates at a partially unconscious level, such norms and values will influence behaviour, even, for example, when individuals think that they are acting impartially and reflexively in an interview situation. It is precisely because of the overlap between decision-making, reflexivity and the unconscious, that we have a better understanding of how these factors intertwine to affect judgment and behaviour. In sum, a more nuanced understanding of how values and dispositions are internalised over time in habitus aids our understanding of how active representation occurs on an everyday basis to reproduce inequality and discrimination.

The obstacles to women's progress in the workplace cannot all be attributed to unconscious bias originating from men. Edwards' et al.'s (2014) research also found that SES and EL women report low self-confidence and self-belief, which acts as an impediment to their career progression (see proposition 4 above). This may result from the cultural and organizational systems, which reinforce messages about women's place, or 'lack of fit', in leadership positions. 
Women reporting low self-confidence and self-belief is a clear case where habitus and the unconscious can help us to better understand how such views take root and are internalized. Habitus allows us to understand how gender stereotyping impact on individuals over the life course. Women, like men, are socialised into gender roles from an early age and, in the case of women, this may, through structural gender discrimination, lead to the inculcation of feelings of self-doubt in relation to various fields, including the workplace. Such feelings may impact on one's workplace behaviour at an unconscious or conscious level, or as a mixture of both. As Bourdieu argues, we each carry in ourselves: 'part of yesterday's man... who inevitably predominates in us, since the present amounts to little compared to the long past' $(1977$, p.79).

As we have seen, unconscious bias as discussed by Edwards et al. (2014) and the extant literature is clearly a term which relates to agency. As such, it is important to think critically, conceptually and in-depth about the concept of agency which underpins it.

\section{A Future Research Agenda}

Ross' Implicit Association Test (2008) discussed earlier, based on social psychology's theory of associationalism, provides the dominant approach to unconscious bias training programmes today. Given the alternative understanding of unconscious bias developed in this article, I argue that attempts to address unconscious bias would benefit from a theorization of the unconscious as formulated in this piece, and related, a methodology drawing on this theoretical frame. Such an approach takes account of the deep underlying structures that shape prejudices, and how they take root over the life course in habitus.

In this section I address the methodological implications of the concept of unconscious bias and the framework outlined here. I consider some of the methodological challenges in researching unconscious bias which will require new methods and techniques of inquiry. Space limitations prevent a detailed exposition of the methodology, here I highlight key principles.

Almost the foundational principle of any social science methodology is to focus upon the visible; whether through documenting the spoken word or the movements of the human body, by the interviewer, the ethnographer or the participant observer. Whilst these issues are certainly worthy of the social scientist's attention, this article seeks to draw attention to those 
aspects of behaviour, which are hidden, elusive and transient; that exist at the level of the unconscious, and which inform unconscious bias.

The starting point of the unconscious bias methodology involves documenting the agent's habitus and its unconscious elements, allowing insight into the individual's unconscious biases. I advocate an approach to habitus in which the researcher attempts to access both the habitus and its unconscious elements through sensitively accessing and revealing layers of habitus using a range of qualitative methodological tools. As such, the outermost layer of habitus is conceptualised as being more accessible than the layers at the core, paralleling the progression from conscious, reflexive and intentional understandings to those which operate at the level of the unconscious.

The first layer of habitus can be accessed using direct, qualitative and in-depth questions, utilising what is usually termed a life-history approach This provides an initial picture of the habitus. Second, one can delve further into habitus by building on the information provided at the first level and using it to construct hypothetical scenarios in interviews with respondents. So, one could locate the individual within these scenarios and ask them how they would react. For example, we might ask individuals how they would respond to a female leader; to colleagues taking maternity leaves or on changes to the gender balance of their office. Finally, for the deepest level of the habitus, the level that it most difficult to penetrate, language analysis or critical discourse analysis could be used. The focus here would be on picking up on the hints or subtle points made during the interview. That which is unsaid, the silences, and that which might be termed non-verbal communication. Together these three strategies could be combined to allow greater knowledge and understanding of an individual's habitus.

I do not have the space to expand further, but the methodology advocated here draws insights from a range of methodological approaches, including conversational analysis, discourseanalytical approaches and interpretive methodologies. At the core of this methodology is a reliance on an in-depth interview method which uses both structured and unstructured questions in a sensitive way to encourage the interviewee to open-up and to be comfortable and communicative in a non-threatening interview environment. Central to this approach must be a concerted effort to document bodily hexis (Bourdieu, 1977) in the interview. So, for example, if the interviewee is being defensive in her body language this should also be documented as part of the interview. 
The unconscious by its very nature will be difficult to capture. The methodology developed here may not give us immediate access to unconscious biases or a complete picture of the unconscious aspects of the habitus, but it will help to capture some sense of the habitus and its unconscious dimension. Time and detailed qualitative engagement with interviewees is paramount to this methodology.

\section{In Conclusion}

As Kingsley stated in 1944, '(B)ureaucracies, to be democratic, must be representative of the groups they serve' (1944: p. 305). Building on Kingsley's (1944) criticisms of the narrow outlook, values and culture of the British Civil Service, subsequent research on representative bureaucracy has furthered our understanding of types of representation, but conspicuously absent in the debate thus far is engagement with concepts of agency and specifically with the unconscious - and the role it plays in understanding how representation occurs at the level of the individual. Addressing this gap, this article has furthered our understanding of how bureaucratic representation occurs, showing how unconscious bias and the unconscious more broadly offers a route through which agents transmit values, culture and biases through active representation, thus enhancing our understanding of what Kingsley and others understood as the influence of pre-employment socialisation on representation in bureaucracies.

This article, in its discussion of agency, develops a conceptual vocabulary to enhance our understanding of how active representation occurs. I develop an approach to the unconscious within a broader notion of habitus as a conceptual frame within which to understand how unconscious bias operates and is implicated in reproducing discrimination. The article also outlines a methodological frame for thinking about how to document unconscious bias based around Bourdieu's notion of habitus. A renewed focus on what we mean by agency and its key capacities will provide Public Administration scholars with a much firmer platform from which to understand and tackle unconscious bias in bureaucracies.

Whilst some progress has been made in tackling the myriad forms of inequality that exist in society, it is clear from the 'Not yet 50/50' report, as well as other research discussed here, that discrimination continues to be a significant issue. To address this problem, it is important to recognise that discrimination can take multiple forms. Just as overt discrimination declined 
through better policing, there is a need to renew efforts to address unconscious bias. One of the aims of this article has been to show that discrimination has become harder to document and track. Crucially, individuals may not even know that they are engaging in discriminatory practices. Gender discrimination in bureaucracies today may, of course, still operate at an explicit and conscious level, but it also functions at a subtler level, and we need better tools and concepts to understand it. The discussion of unconscious gender bias here serves as an illustration of an issue that may extend to other forms of discrimination, such as race, class and disability. As such, the concept of unconscious bias discussed here has relevance beyond a focus on gender.

\section{Bibliography}

AIM (2011). Gender Diversity in Management. Aim Insights. Green Paper.

Akram, S. (2012). Fully Unconscious and Prone to Habit: The Characteristics of Agency in the Structure and Agency Dialectic. Journal for the Theory for Social Behaviour. Vol. 43 (1). pp.45-65.

Akram, S. and Hogan, A. (2015). On Reflexivity and the Conduct of the Self in Everyday Life: Reflections on Bourdieu and Archer. British Journal of Sociology. Vol 66 (4) pp. 606-625.

Andrews, R. and Miller, K.J. (2013). Representative Bureaucracies, Gender and Policing: The Case of Domestic Violence Arrests in England. Public Administration. Vol. 91 (4.) pp. 998-1014.

Archer, M. (2012). The Reflexive Imperative in Late Modernity. Cambridge: Cambridge University Press

Arcuri L, Castelli L, Galdi S, Zogmaister C, Amadori A. (2008). Predicting the vote: Implicit attitudes as predictors of the future behavior of decided and undecided voters. Political Psychology. 29: 369-387.

Atkins, D. N. and V. M. Wilkins. 2013. Going beyond reading, writing and arithmetic: The effects of teacher representation on teen pregnancy rates. Journal of Public Administration Research and Theory. Vol. 23. No. 4. Pp.771-790.

Australian Department of Defence. (2011). The Review of Employment. Pathways for APS Women in the Department of Defence. Department of Defence: Australian Government.

Australian Department of Treasury (2011). Progressing Women. The Treasury: Australian Government. 
Australian Public Service Commission (APSC). (2012), State of the Service Report 20112012. Australian Commonwealth Government.

Birch, A. (1964). Representation and Responsible Government. London: Allen and Unwin.

Bohnet, I. (2016). What works? Harvard University Press.

Bourdieu, P. (1977). Outline of a Theory of Practice. Cambridge: Cambridge University Press.

Bourdieu, Pierre. (1990). In Other Words: Essays Towards a Reflexive Sociology. Stanford: Stanford University Press.

Burdein, I., Lodge, M., \& Taber, C. S. (2006). Experiments on automaticity and of political beliefs and attitudes. Political Psychology, 27, 359-371.

Catalyst. (2004). The bottom line: Connecting corporate performance and gender diversity. New York: Catalyst.

Christensen, J., Bekerom, P.V.D. and Voet, J. V.D. (2017). Representative bureaucracy and Specialist Knowledge in the European Commission. Public Administration. Vol. 95 (2). Pp. 450-267.

Edwards. M. Burmester, B. Evans, M. Halupka, M. May, D. (2014). 'Not Yet 50/50: Barriers to the progress of senior women in the Australian Public Service'. ANZSOG, University of Canberra, Australia.

Elder-Vass, D. (2007), 'Reconciling Archer and Bourdieu in an Emergentist Theory of Action’. Sociological Theory. 25: 325-46.

Evans. M., and Edwards, M. (2014), "Debate: Phasma”, Australian Journal of Public Administration, 73, 4, pp. 514-516.

Evans. M, Edwards, M. Burmester, B, May, D. (2014). 'Not yet 50/50' - Barriers to the Progress of Senior Women in the Australian Public Service. Australian Journal of Public Administration. Vol. 73 (4). Pp. 501-510.

Freud, S. (1927/1962). The Ego and the Id. London: The Hogarth Press and the Institute of Psychoanalysis.

Gaertner, S.L. and Dovidio, J.F. (2005). Social Psychology Understanding and Addressing Contemporary Racism. Journal of Social Issues. Vol. 61 (3). Pp. 615-639.

Galdi; Gawronski and Arcuri (2015). What Can Political Psychology Learn from Implicit Measures? Political Psychology. Vol 36 (1).

Genat, A., Wood, R. and Sojo, V. (2012). Evaluation Bias and Backlash. Melbourne Business School. 
Greenwald, A. G. and Banaji M. (1995). Implicit Social Cognition: Attitudes, Self-Esteem, and Stereotypes. Psychological Review. 1995. Vol. 102. (1). Pp.4-27.

Jenkins, R. (2002). Pierre Bourdieu. London: Routledge.

Johnston, M, K. (2017). A Gender Analysis of Women in Public-Private-Voluntary Sector 'Partnerships'. Public Administration. Vol. 95 (1). Pp. 140-159.

Kingsley, J.D. (1944). Representative bureaucracy. The Antioch Press, Yellow Springs

Krislov, S. (1974). Representative Bureaucracy. Englewood Cliffs. NJ: Prentice Hall.

Krislov, S. and Rosenbloom, D. (1981) Representative Bureaucracy and the American Political System. New York: Praeger.

Linos, E., Reinhard, J., and Rude, S. (2017 forthcoming). Levelling the playing field in police recruitment: Evidence from a field experiment on test performance. Public Administration.

Mackay, F. and Rhodes, R.A.W. Gender, Greedy Institutions and the Departmental Court. (2013). Public Administration. Vol 91. (3). Pp. 582- 598.

McKinsey and Company (2011) Women Matter: Making the Breakthrough. McKinsey and Company.

McNay, L. (1999). 'Gender, Habitus and the Field: Pierre Bourdieu and the Limits of Reflexivity'. Theory, Culture and Society. 16(1): 95-116

Meier, K.J., and Nicholson-Crotty, J. (2006). Gender, representative bureaucracy, and law enforcement: The case of sexual assault. Public Administration Review. Vol. 66. 850-860

Mosher, F. (1968/1982). Democracy and the Public Service. New York: Oxford University Press.

Payne, B.K., and Gawronski, B., (2010). A history of implicit social cognition in Gawronski, B., Payne, B.K. (Eds.), Handbook of Implicit Social Cognition: Measurement, Theory, and Appli-cations. Guilford Press: New York.

Phelps, E. A., O'Connor, K. J., Cunningham, W. A., Funayama, E. S., Gatenby, J. C., Gore, J. C., and Banaji, M. R. (2000). Performance on indirect measures of race evaluation predicts amygdala activation. Journal of Cognitive Neuroscience. Vol.12(5), 729-738.

Pitkin, H. (1967). The Concept of Representation. Berkeley: University of California Press.

Pitts, D.,W. (2005). Diversity Representation and performance: Evidence about Race and Ethnicity in Public Organizations. Journal of Public Administration Research and Theory. Vol.15 (4). 615-31. 
Riccucci, N. M. and G. G. Van Ryzin. (2016). Representative Bureaucracy: A Lever to Enhance Social Equity, Coproduction, and Democracy. Public Administration Review. Vol. 77. No. 1. pp. 21-30.

Ross, H. (2008). Proven Strategies for addressing unconscious bias in the workplace. CDO Insights.

Saltzstein, G.H. (1979). Representative Bureaucracy and Bureaucratic Responsibility. Administration and Society. Vol. 10: 465-475.

Sanders, M., Hrdlicka J., Hellicar, M., Cattrell, D., Knox, J. (2011). What stops women from reaching the top? Bain and Company.

Singh, D., S. (2005). Preconscious influences on decision making about complex questions. Unpublished $\mathrm{PhD}$ thesis. Available from University of Melbourne.

Skorkjaer, A. B. (2011). Diversity and dominance in the Arctic. Ethnic relations in the Greenlandic Bureaucracy. Public Administration. Vol. 89 (2). Pp. 522-536.

Sowa, J.E., and Seddon, S.C. (2003). Administrative Discretion and Active Representation: An Expansion of the theory of Representative Bureaucracy. Public Administration Review. Vol. 63 (6). Pp.700-710.

Stanley,D., Phelps,E., \& Banaji, M. (2008). The Neural Basis of Implicit Attitudes. Current Directions in Psychological Science.Vol 17(2). pp. 164 - 170

Stazyk, E.C., Davis, R.S., Portillo, S. (2017 forthcoming) More dissimilar than alike? Public values preferences across US minority and white managers. Public Administration.

Swartz, D. (2002). The Sociology of Habit. The Perspective of Pierre Bourdieu. Occupation, Participation and Health. Vol. 22 (1).

Thompson, F. J. (1976). Minority Groups in Public Bureaucracies: Are Passive and Active Representation Linked? Administration and Society. Vol. 8: 201-226.

Wilkins, V.M. (2007). Exploring the causal story: Gender, active representation, and bureaucratic priorities. Journal of Public Administration Research and Theory. Vol 17. Pp. 77-9. 